\title{
AMPLIAÇÃO DO PAPEL COGNITIVO DO RÉU NO PROCESSO: ANÁLISE DO BINÔNIO RISCO X RESPONSABILIDADE ${ }^{1}$
}

\section{EXPANDING THE COGNITIVE ROLE OF THE DEFENDANT IN THE \\ PROCESS: ANALYSIS OF THE RISK X RESPONSIBILITY}

José Henrique Mouta Araújo

Doutor e mestre e em direito (UFPA), com estágio de pósdoutoramento na Faculdade de Direito da Universidade de Lisboa, professor do Centro Universitário do Estado do Pará (CESUPA) e do Instituto Brasileiro de Ensino, Desenvolvimento e Pesquisa (IDP), procurador do Estado do Pará e advogado. Belém/PA. E-mail: henriquemouta@uol.com.br. ORCID: https://orcid.org/00000002-3874-8511.

RESUMO: Este ensaio procura refletir sobre os riscos e as responsabilidades das partes no processo, com a análise de institutos jurídicos e a ampliação dos poderes do réu na formação de títulos executivos judiciais em seu favor: dependendo das situações ocorridas no curso do processo, as posições processuais podem ficar invertidas.

PALAVRAS-CHAVE: Partes; Processo; Títulos; Execução; Responsabilidade; Risco.

\begin{abstract}
This essay seeks to reflect on the risks and responsibilities of the parties in the process, with the analysis of legal institutes and the expansion of the defendant's powers in the formation of judicial executive titles in his favor: depending on the situations that occurred in the course of the process, the procedural positions may be reversed.
\end{abstract}

KEYWORDS: Parties; Process; Titles; Execution; Responsibility; Risk.

\footnotetext{
${ }^{1}$ Artigo recebido em 13/04/2021 e aprovado em 30/06/2021.
} 
Sumário. 1. Introdução. 2. Forma da reconvenção e direitos favoráveis ao réu na própria contestação. 3. A formação de títulos judiciais em favor do réu: alteração dos polos originários da relação processual no pedido contraposto e ação dúplice. 4. Conclusões. 5. Referências bibliográficas

\section{Introdução}

O presente texto pretende rediscutir o papel do réu no processo de conhecimento, superando a clássica afirmação de que sua conduta seria apenas passiva (impedimento à pretensão do autor).

Em várias situações jurídicas o legislador apresenta caminhos para esta superação conceitual, inclusive com possibilidade de formação de títulos executivos judiciais em favor do demandado originário.

Nos casos de ação própria conexa à do autor, bem como em várias situações envolvendo a improcedência do pedido do demandante, há a possibilidade de certificação de direito em favor do réu originário, pelo que a análise concreta deve ser feita com muita cautela. O problema central a ser enfrentado envolve as múltiplas possibilidades de inversão dos polos da relação processual e seus reflexos práticos.

Serão analisadas, com demonstração doutrinária e jurisprudencial, as diversas situações em que pode ser apresentada pretensão do próprio réu em desfavor do autor originário, constituindo título judicial invertido, como nos casos de reconvenção, contradireitos, tutela provisória não confirmada, ações dúplices, etc.

Vamos aos argumentos.

\section{Forma da reconvenção e direitos favoráveis ao réu na própria contestação}

O primeiro aspecto a ser debatido, em relação à ampliação do papel cognitivo do réu no processo, diz respeito à forma e estrutura da reconvenção, considerando, para tanto, a concentração da defesa em peça única e as múltiplas possibilidades do demandado em juízo. 
Neste sentido, uma questão que restou superada com o CPC atual foi a forma de apresentação da reconvenção: se em peça própria ou em capítulo da contestação ${ }^{2}$.

Como é sabido, a reconvenção é ação do réu em face do autor no mesmo processo, gerando uma cumulação ulterior de pedidos que devem, em regra, ser julgados na mesma sentença ${ }^{3}$.

Ela demonstra uma clara atuação positiva do réu no processo originário, deixando de ter uma conduta meramente defensiva, para também pleitear tutela jurisdicional a seu favor e, com a modificação advinda da legislação processual de 2015, dentro da própria estrutura da contestação.

É necessário ressaltar, portanto, que a cumulação de pedidos pode advir de manifestação do autor, como os pedidos cumulados na sua petição inicial (art. 327, do CPC), ou por ato do réu, com a apresentação da reconvenção como capítulo autônomo da peça contestatória. Há, portanto, a ampliação objetiva ${ }^{4}$ e, também, nos casos previstos nos $\S \S 3^{\circ} \mathrm{e}$ $4^{\circ}$, do art. 335, subjetiva.

$\mathrm{O}$ art. 335, do CPC, exige a propositura da reconvenção como capítulo da contestação, onde o réu (reconvinte) aduz demanda própria contra o autor (reconvindo), conexa à ação principal ou ao fundamento da defesa.

A reconvenção, como bem entendeu o STJ no REsp 1775812 / RJ (Rel. Min. Marco Aurélio Bellizze - $3^{\mathrm{a}} \mathrm{T}$ - J. em 19/03/2019 - DJe de 22/03/2019), “é técnica por meio da qual se objetiva a otimização da eficiência processual, potencializando o resultado de pacificação social, ao agregar a um mesmo processo uma segunda demanda proposta pelo

\footnotetext{
${ }^{2}$ No CPC/73, a contestação e reconvenção eram apresentadas em peças processuais autônomas (art. 299). Contudo, no atual Código, visando atender a concentração da defesa, a reconvenção passou a ser apresentado como capítulo da contestação. Mesmo no sistema processual anterior, admitia-se que a apresentação em conjunto da contestação e reconvenção constitui falha que não gerava prejuízo ao regular processamento do feito. No tema, ver: BONDIOLI, Luis Guilherme Aidar. Reconvenção no processo civil. São Paulo: Saraiva, 2009.

3 "A reconvenção consiste em ampliação objetiva da demanda, pelo réu, no mesmo processo. É o contra-ataque do réu face ao autor. Verdadeira cumulação de pedidos, veiculada por partes contrapostas." MALAFAIA, Evie Nogueira e. Comentário ao art. 343. Novo código de processo civil comentado - Tomo II (art. 318 ao art. 770). RIBEIRO, Sergio Luiz Almeida; GOUVEIA FILHO, Roberto Pinheiro Campos; PANTALEÃO, Izabel Cristina; GOUVEIA, Lucio Grassi de (coords). São Paulo: Lualri, 2017. p. 70

${ }^{4}$ No tema, vale citar Paulo Henrique dos Santos Lucon: "Há, portanto, além da demanda originária, a demanda ulterior proposta pelo reconvinte em face do reconvindo, com a nítida ampliação do objeto do processo. A reconvenção é então demanda incidente a ser proposta perante o juiz da causa para manifestar pretensão própria, conexa com a demanda principal ou com o fundamento da defesa (CPC, art. 343). Relação entre demandas. 2ª edição. Brasília: Gazeta Jurídica, 2018, p. 123.
} 
réu contra o autor, ainda que não exclusivamente essas partes, e fora dos limites da ação original".

A legislação processual de 2015 atendeu, de um lado, o fenômeno da concentração dos instrumentos de atuação do ré u em peça própria e, de outro, buscou alcançar maior celeridade na tramitação das várias ações (vários pedidos) que podem ser provocados no mesmo processo.

Em verdade, essa concentração de manifestações do réu em única peça alcançou também institutos que eram formulados em peça única, na legislação processual anterior, como a incompetência relativa, a incorreção do valor da causa e a correção do polo passivo (art. 337, II e III, 338 e 338, do CPC).

Duas indagações são muito comuns na prática forense: há preclusão em caso de não propositura de reconvenção $o^{5}$ ? O réu pode ser revel e reconvinte ao mesmo tempo?

A ampliação objetiva e, por vezes, subjetiva advinda da reconvenção deve atender os regramentos mencionados anteriormente. Logo, se o réu tem pretensão em desfavor do autor sem qualquer aderência (conexão) em relação à causa originária, não deve apresentar reconvenção, e sim demanda própria, sem que ocorra a preclusão. Da mesma forma, mesmo em caso de conexão, o réu pode preferir demandar de forma autônoma, sem prejuízo da distribuição por dependência (arts. $55, \S 1^{\circ}$ e $3^{\circ}$, do CPC).

A apresentação de reconvenção também gera autonomia na fixação de honorários advocatícios, como bem entendeu o item 1 do AgInt no AREsp 1109022 / SP (STJ - Rel. Min. Luis Felipe Salomão - 4 ${ }^{\mathrm{a}}$ T- J. em 29/04/2019 - DJe 02/05/2019): “1. "Os honorários na reconvenção são independentes daqueles fixados na ação principal, independentes, inclusive, do resultado e da sucumbência desta. Precedentes." (AgR-AG n. 690.300/RJ, Rel. Min. Massami Uyeda, 4a Turma, unânime, DJU de 03.12.2007)”.

\footnotetext{
${ }^{5}$ No STJ existem precedentes enfrentando problema comum no sistema processual anterior, que era o oferecimento da reconvenção posteriormente à contestação e a ocorrência de preclusão. Ver: RESP 1502781SP, ARESP 982252-SP,RESP 1035027-AL, RESP 1415879-SP, RESP 1242177-PR. Vale transcrever parte da ementa do REsp 1634076 / PE (Rel. Min. Nancy Andrighi - 3a T - J. em 06/04/2017 - DJe 10/04/2017): “4. Ao não reconhecer a preclusão consumativa para oferecimento da reconvenção que, mesmo apresentada dentro do prazo legal de resposta do réu não foi feita simultaneamente com a contestação - como exige a lei processual civil -, o juízo de $1^{\circ}$ grau, bem como o TJ/PE, em sede de análise de reexame necessário, incorreram em inegável violação a literal disposição de lei, hábil a autorizar o manejo da ação rescisória".
} 
Por todas essas razões, não é obrigatória a propositura de reconvenção, mesmo estando presentes seus requisitos, tratando-se de mera oportunidade processual assegurada ao réu 6 .

De outra banda, o $\S 6^{\circ}$, do art. 343 , do CPC, consagra que o réu pode reconvir sem contestar. Como seria essa atuação, se a reconvenção é um capítulo da reconvenção? Não se pode esquecer que o sistema processual labora com o binômio risco x responsabilidade, pelo que o réu tem o ônus de contestar e reconvir na mesma peça processual.

Contudo, se preferir apenas apresentar, neste momento, a reconvenção dentro da contestação, sofrerá as consequências advindas da presunção da veracidade dos fatos autônomos suscitados pelo autor na sua peça de ingresso. Só existirá um capítulo nesta peça processual denominada contestação, que é a reconvenção, com requerimentos positivos formulados pelo reconvinte.

Assim, apesar da indicação contida no caput do art. 343, do CPC, não há óbice à apresentação tão-somente da reconvenção, sofrendo o réu as consequências de sua conduta omissiva em relação aos fatos alegados pelo autor em sua inicial. Será, portanto, revel na ação, e reconvinte, sendo o seu contra-ataque suficiente para afastar os efeitos da revelia em relação aos fatos comuns (arts. 341 e 344, do CPC).

Portanto, poderá adotar uma conduta omissiva (revelia na ação) e ativa (reconvenção) simultaneamente, com consequências processuais em cada um dos capítulos do mesmo processo.

De outro prisma, é possível a ocorrência de revelia do autor na reconvenção, bem como a desistência ou outra causa que venha extinguir parcialmente o processo em relação à ação, o que não altera o prosseguimento da reconvenção (art. $343, \S \S 1^{\circ}$ e $2^{\circ}$, do CPC), com a possibilidade de formação de título executivo judicial em favor de uma ou ambas as partes, em capítulos decisórios diferentes.

\footnotetext{
6 “Imagine-se que o autor cobra $\mathrm{R} \$ 200$ mil. O réu reputa possuir, em face do autor, crédito líquido, certo e exigível de $\mathrm{R} \$ 270$ mil. Se ele pretende apenas invocar a compensação como matéria de defesa, basta-lhe alegar tal matéria em sua contestação. Nesse caso, se procedente essa defesa, ele obterá a integral improcedência do pedido do autor, com a compensação dos créditos até o limite de $\mathrm{R} \$ 200$ mil. Mas, para cobrar a diferença de R \$ 70 mil, o réu precisará formular pretensão própria, mediante ação autônoma ou como reconvenção no processo. Nesse caso, a reconvenção será conexa à contestação apresentada pelo réu". WAMBIER, Luiz Rodrigues e TALAMINI, Eduardo. Curso avançado de processo civil. Vol 2, $18^{a}$ edição. São Paulo: Revista dos Tribunais, 2019, p. 161.
} 
Logo, é nítida, apesar da necessidade de conexão, a autonomia entre a reconvenção e a ação. Não pode o autor, sabedor do risco e responsabilidade de demandar em juízo, se beneficiar pela sua própria atuação açodada em caso de apresentação de reconvenção. A atividade jurisdicional não é uma loteria. Mesmo em caso de desistência da ação ou extinção parcial do processo, é admitido o prosseguimento do feito para apreciação e julgamento da reconvenção que, em última análise, pode gerar título executivo judicial (art. 515, I, do CPC) em favor do réu.

O risco e a análise econômica da litigância devem ser sopesados por ambas as partes, à semelhança do que também ocorre nos casos em que se admite pedido contraposto e nas ações dúplices, como será melhor analisado em seguida ${ }^{7}$.

No mesmo sentido, não há qualquer impedimento para julgamento parcial do mérito, com acolhimento da ação ou da reconvenção, e continuidade em relação à outra demanda cumulada (art. 356, do CPC) ${ }^{8}$. Pelo contrário, a resolução parcial também deve ser admitida nos casos em que a cumulação de pedidos advém de conduta do réu, com o procedimento previsto no art. 356, do CPC, o que também será objeto de enfrentamento em capítulos seguintes deste curso.

Outrossim, algumas matérias, com pleitos favoráveis ao réu, podem ser suscitadas sem a necessidade de reconvenção.

\footnotetext{
${ }^{7}$ Como bem afirma Araken de Assis: "por intermédio dessa pretensão e conforme à natureza do bem da vida pleiteado, eventual sucesso garantirá ao réu proveito maior que o do autor. As posições recíprocas das partes invertem-se radicalmente: o réu originário assume a condição de autor e o autor primitivo a de réu, recebendo as partes, nessa nova qualidade, a denominação peculiar de reconvinte e de reconvindo. O reconvindo necessita defender-se contra a pretensão do reconvinte de forma análoga à que impôs ao réu. Logo, a disciplina própria de autor e de réu aplica-se integralmente às novas posições das partes. Por um lado, o pedido do reconvinte há de revestir-se dos requisitos do art. 319; de outro, a defesa do reconvindo tem os ônus e os poderes inerentes a esse polo da relação processual". Processo civil brasileiro. Vol III, parte especial: procedimento comum. São Paulo: Revista dos Tribunais, 2015, pp. 215 e 216.

8 “O julgamento conjunto dos pedidos contrapostos não é inexorável. $\mathrm{O}$ art. $343, \S 2^{\circ}$, consagrou o princípio da autonomia das pretensões. Logo, o reconhecimento do pedido, formulado pelo reconvindo no prazo da resposta, ensejará a precipitação do julgamento, na forma do art. 354, caput, e parágrafo único, c/c art. 487, III, a. O recurso cabível é o agravo de instrumento. O processo prosseguirá com os trâmites da pretensão processual originária. Não há, absolutamente, obrigatoriedade no julgamento conjunto do mérito. A concentração do juízo de mérito vale para cada pretensão isolada. E da unidade da relação processual, apesar de complexo o objeto do processo, retira-se argumento favorável ao julgamento separado, quando possível, das pretensões contrapostas". ASSIS, Araken de. Processo civil brasileiro. Vol III, parte especial: procedimento comum. São Paulo: Revista dos Tribunais, 2015, p. 243. O autor, inclusive, cita o acórdão do STJ RESp 341.417 ( $1^{\mathrm{a}} \mathrm{T}$ - Rel. Min. Garcia Vieira - J. 19.02.2002).
} 
Destarte, alguns direitos, ou contradireitos ${ }^{9}$, que podem gerar decisões favoráveis ao réu, podem ser suscitados na peça contestatória (no capítulo propriamente dito da defesa), independente de reconvenção ${ }^{10}$.

Portanto, na peça única de contestação, há a possibilidade de condutas negativas (ou impeditivas do suposto direito do autor) e positivas que podem constituir, em momento futuro, títulos judiciais em favor do réu.

Como se pode perceber, houve uma preocupação, pelo legislador de 2015, com o fator tempo de duração do processo e com os múltiplos incidentes que podem ser gerados a partir da atuação positiva do réu no processo, pelo que consagrou a concentração dos incidentes processuais na peça processual única (contestação).

Apesar do nome ter sido mantido o mesmo (contestação), esta manifestação pode conter fundamentos de defesa, provocação de contradireitos, além de verdadeiro contraataque, inclusive formando título executivo judicial a seu favor, como restará claro a seguir.

\section{A formação de títulos judiciais em favor do réu: alteração dos polos originários da relação processual no pedido contraposto e ação dúplice}

Além da questão ligada à estrutura da peça única, com requerimentos negativos e positivos em favor do réu, a sua condição variável na fase de cumprimento de sentença pode ser observada outros casos que merecem reflexão.

Em situações que tradicionalmente já estavam previstas desde o CPC/73, há outras possibilidades de formação de títulos executivos em favor do réu que, na fase de cumprimento de sentença, passa a ser considerado exequente.

Aliás, desde já vale mencionar que a consagração da parte como credora (autoralexequente) ou devedora (rélexecutada) deve ser analisada de acordo com o momento e o que no título executivo judicial estiver consignado. As situações processuais

\footnotetext{
9 “A decisão que não acolhe a afirmação de contradireito é decisão de improcedência desta afirmação. Como tal, se subsome ao inciso I do art. 487 (ou ao inciso II, que cuida da prescrição, mas que pode ser aplicado por analogia à rejeição dos demais contradireitos). É decisão de mérito, apta à coisa julgada”. DIDIER JR, Fredie. Contradireitos, objeto litigioso do processo e improcedência no CPC-2015. In Improcedência. MOUZALAS, Rinaldo; SILVA, Beclaute Oliveira e MARINHO, Rodrigo Saraiva. Salvador: Juspodivm, 2015, p. 72.

${ }^{10}$ No tema, vale fazer a leitura do Acórdão REsp 1524730/STJ - Rel. Min. Ricardo Villas Bôas Cueva - $3^{\mathrm{a}}$ Turma - J. em 18/08/2015 - DJe 25/08/2015.
} 
podem ser alteradas dependendo do andamento do processo e do resultado de algum pronunciamento judicial proferido ${ }^{11}$.

A fase de cumprimento de sentença pode provocar, além da inversão dos polos da relação processual, a inclusão de parte que originariamente era estranha à relação processual, como na hipótese de aplicação de multa à autoridade coatora no Mandado de Segurança (inclusive com a possibilidade de manejo de recurso - art. 14, §2º da Lei 12.016/09).É razoável afirmar, portanto, que diversas situações jurídicas permitem a constituição de título executivo em favor do réu originário, gerando, inclusive, liquidação e cumprimento de sentença invertidos (vg. art. 302, parágrafo único, do CPC).

Neste contexto, devem ser separadas duas hipóteses distintas: aquelas em que o réu deve promover demanda ou provocação judicial própria e as situações em que, pela própria natureza do título e do requerimento provisório pleiteado pelo autor, há certificação de existência de direito em favor do demandado.

No primeiro grupo, poder-se-á indicar as situações de requerimentos positivos formulados pelo então réu, como na reconvenção, que já foi tratada anteriormente (art. 343 do CPC) e no pedido contraposto dos juizados especiais (art.31, da Lei 9.099/95).

No segundo, os exemplos são as tutelas provisórias de urgência não confirmadas ou nas demais situações previstas no art. 302, do CPC, as sentenças de improcedência que podem reconhecer a exigibilidade de obrigação de pagar (art. 515, I, do CPC), a execução provisória considerada injusta - quando o recurso pendente desconstitui o título executivo provisório (art. 520, I, do CPC) e a ação de execução atingida, por exemplo, pela procedência dos embargos do devedor (art. 776, do CPC), etc.

O binômio a ser enfrentado é o mesmo citado anteriormente: risco $X$ responsabilidade. Em várias situações o direito do réu pode ser certificado judicialmente, com eventual inversão das posições processuais no momento do cumprimento de sentença.

Na reconvenção, como já mencionado, há a necessidade de comprovação da conexão em relação à demanda proposta pelo reconvindo ou ao fundamento da defesa (art. 343, do

\footnotetext{
11 "O réu também pode demandar, embora com pedidos bastante peculiares. Pode pedir o réu, em sua peça de defesa: $a$ ) extinção do processo sem exame do mérito; $b$ ) a remessa dos autos ao juízo competente ou ao juízo prevento; $c$ ) a devolução do prazo de defesa; $d$ ) a improcedência do pedido do autor; $e$ ) a condenação do autor às verbas de sucumbência; $f$ ) condenação do autor por litigância de má-fé; $g$ ) a sua pretensão dúplice nos caos de ação dúplice, como as ações meramente declaratórias". DIDIER JR, Fredie. Curso de Direito Processual Civil vol 1. 17 a edição. Salvador: Juspodivm, 2015, p. 656.
} 
CPC/15), ampliando o objeto litigioso do processo, com a formação de sentença em capítulos $^{12}$.

Assim, analisando o todo (processo) como módulos autônomos, nada impede que, no capítulo (módulo) ação, o pedido do autor seja julgamento total ou parcialmente procedente, e, dependendo do caso concreto, a reconvenção ser acolhida em favor do reconvinte, o que irá configurar, na fase de cumprimento de sentença, a possibilidade de atos expropriatórios de mão dupla ${ }^{13}$. Esta multiplicidade de atuações na fase de conhecimento e de cumprimento é permitida no sistema processual, pelo que se pode ratificar que o processo deve ser analisado como módulos de um todo, de certa forma autônomos, inclusive no que respeita ao titular do crédito ou débito na fase de cumprimento de sentença advinda de certificação de direito ocorrida na fase anterior (art. 515, I do CPC).Outrossim, nos casos em que se admite pedido contraposto (art. 31, da Lei 9.099/95), a preocupação do legislador é com a simplificação procedimental. Não se deve esquecer que o pedido contraposto deve estar circunscrito aos limites da demanda formulada pelo autor, ao contrário da reconvenção ${ }^{14}$.Realmente, enquanto na reconvenção há demanda do reconvinte em face do reconvindo, cujo requisito principal é a conexão (art. 343, do CPC/2015), gerando uma sentença em capítulos, no pedido contraposto há clara limitação cognitiva, quer pelo pedido formulado pelo autor, quer quanto a impossibilidade de ampliação do objeto (como ocorre na reconvenção), ou mesmo pela necessidade de ficar adstrito à matéria de competência do juizado especial.

Assim, em ambas as hipóteses, há possibilidade de formação de título executivo invertido - em favor do réu originário, pelo que ratifico o mencionado anteriormente: as posições processuais são variáveis e dependerão do módulo processual analisado.

\footnotetext{
12 "Afirma-se em doutrina que na reconvenção o réu se afasta da posição passiva, própria da contestação, para assumir posição ativa, pleiteando um bem da vida em pedido dirigido contra o autor da ação originária". NEVES, Daniel Amorim Assumpção. Novo Código de Processo Civil comentado artigo por artigo. $2^{\mathrm{a}}$ edição. Salvador: Juspodivm, 2017, pp. 623-624.

${ }^{13}$ Sobre o tema, ver ARAÚJO, José Henrique Mouta. Objeto litigioso do processo: reflexões sobre o tema. In Teoria do Processo - panorama doutrinário mundial, vol 2. Fredie Didier Jr (organizador). Salvador: Juspodivm, 2010, pp. 405-425.

${ }^{14}$ Como bem ressaltam Joel Dias Figueira Júnior e Maurício Antônio Ribeiro Lopes, ao comentarem o procedimento dos juizados especiais: "não se deve confundir reconvenção - proibida nestes Juizados, conforme art. 31 - com a formulação de pedidos contrapostos. Aquela é mais ampla e pode perfeitamente superar o espectro da causa petendi e do petitum articulados pelo autor; por sua vez, a contraposição de pedidos ou a contrapretensão limita-se aos contornos dos elementos da ação oferecidos pelo autor". Comentários à lei dos juizados especiais cíveis e criminais. 3. ed. São Paulo: RT, 2000. p. 247.
} 
A mesma possibilidade de variação das posições processuais ocorre nos casos de ações dúplices (v.g, ações possessórias - arts. 554-568, e consignação em pagamento- arts. 539-548, do $C P C$ ), em que, pela própria natureza do direito material, a simples improcedência do pleito do autor já certifica direito em favor do réu. Além disso, é formado o título em favor do demandado também nas hipóteses expressamente previstas no art. 556, do CPC, em que este formula pleito possessório e indenizatório.

Vejamos um exemplo: em caso de improcedência de demanda possessória e acolhimento da tese indenizatória formulada pelo réu (art. 556 do CPC), a sentença certifica direito a seu favor, sendo possível a provocação da fase de cumprimento visando, quem sabe, obrigar o autor a uma conduta (fazer ou não fazer - art. 497-501, do CPC) ou mesmo pagamento de quantia (art. 520-522, do CPC). Percebe-se, com isso, que nas ações dúplices, permite-se a ampliação objetiva ${ }^{15}$, sendo clara hipótese de cumprimento de sentença invertido.

São, portanto, três situações distintas. A primeira é genérica, em que o réu apresenta seu pleito via reconvenção. A segunda, no pedido contraposto, e a última, nas ações dúplices ${ }^{16}$.

Existem, além desses casos, situações em que esta inversão dos polos originários da demanda decorre de tutelas provisórias de urgência, não confirmadas posteriormente (art. 302 do CPC), além dos casos específicos da execução provisória de sentença (art. 520, I e $\S 4^{\circ}$, do CPC) Mais uma vez deve ser enfrentado o binômio risco X responsabilidade.

Com efeito, caso o autor obtenha a seu favor uma tutela provisória (art. 302 do CPC/2015), há, em verdade, uma antecipação provisória de uma situação ligada ao futuro bem jurídico, que poderá ou não ser confirmado. Nesta hipótese, é possível a formação de título executivo invertido quando a confirmação não ocorrer, com possibilidade de liquidação e indenização dos danos causados ao réu no mesmo processo.

\footnotetext{
${ }^{15}$ Vale citar os ensinamentos de Kazuo Watanabe: "em casos excepcionais se permite o alargamento do objeto litigioso através da contestação. Quando isto se permite, diz-se que a ação tem caráter dúplice. A contestação, nessa modalidade de ação, não somente formula defesa do réu, como também poderá conter autênticos pedidos em seu favor, sem necessidade de reconvenção". WATANABE, Kazuo. Ação dúplice. Revista de Processo. n. 31. São Paulo: Revista dos Tribunais, 1983. p. 141.

${ }^{16}$ Como exemplo, é possível indicar o art. $545, \S 2^{\circ}$, do CPC/2015 onde se percebe que, na consignação em pagamento, há a possibilidade de reconhecimento de obrigação dirigida ao autor (devedor) e, consequentemente, formação de título executivo objeto de futuro cumprimento de sentença, favorável ao réu (credor).
} 
A $2^{a}$ Seção do STJ, após a afetação, enfrentou o tema no julgamento do REsp 1.548.749/RS, consagrando expressamente que:

"A obrigação de indenizar o dano causado pela execução de tutela antecipada posteriormente revogada é consequência natural da improcedência do pedido, decorrência ex lege da sentença, e, por isso, independe de pronunciamento judicial, dispensando também, por lógica, pedido da parte interessada. A sentença de improcedência, quando revoga tutela antecipadamente concedida, constitui, como efeito secundário, título de certeza da obrigação de o autor indenizar o réu pelos danos eventualmente experimentados, cujo valor exato será posteriormente apurado em liquidação nos próprios autos" ${ }^{17}$.

Este é exatamente o que se pretende analisar neste momento. A constituição de título executivo em favor do réu originário é consequência natural do insucesso da demanda judicial em que foi concedida a tutela provisória de urgência.

São múltiplas as situações em que o módulo executivo por ser provocado pelo réu originário. Os polos processuais podem ser alterados a depender das circunstâncias da causa e dos benefícios que podem ter sido gerados em decorrência da tutela provisória não confirmada posteriormente (art. 302, do CPC).

Como se pode perceber, em caso de medida judicial provisória (cumprimento provisório - arts. 520-522, do CPC/15 e tutela provisória de urgência) o resultado final da demanda poderá configurar uma inversão de polos, com liquidação e cumprimento nos próprios autos originários ${ }^{18}$. O processo, como um todo, pode provocar vários incidentes que alteram os polos originários, com eventual cumprimento de sentença invertido e sincrético em desfavor daquele que provocou a tutela jurisdicional.

Neste contexto, aliás, é interessante notar que às vezes o demandado nem mesmo terá direito à caução como condicionante às situações previstas no art. 521, do CPC/15.

\footnotetext{
${ }^{17}$ Importante fazer a leitura do posicionamento da $3^{\mathrm{a}}$ Turma do STJ, no REsp 1770124 / SP (Rel. Min. Marco Aurélio Bellize - J. em 21.05.2019 - DJe de 24/05/2019 - RSTJ vol. 255 p. 739).

18 Já se observou em outra oportunidade que o provimento do recurso e a caracterização da execução como injusta irá ensejar a inversão dos polos da relação processual, sendo possível ao executado buscar a liquidação e posterior execução dos danos causados em razão da precipitação da execução por parte do então credor. Destarte, "há uma inversão das posições processuais e de títulos executivos. A execução provisória considerada injusta pelo provimento do recurso pendente ocasionará, se for o caso, o resgate da caução, além da possibilidade de indenização pelos prejuízos causados, passando o primeiro exeqüente (cujo título foi fulminado pelo provimento do recurso) a ser executado pelo pelos danos causados ao antigo executado, que passará a ser o novo exeqüente”. ARAÚJO, José Henrique Mouta. Anotações sobre a nova disciplina da execução provisória e seus aspectos controvertidos. Revista Dialética de Direito Processual n. 14. maio. São Paulo: Dialética, 2004. p. 57.
} 
Destarte, na busca de maior celeridade ao procedimento da execução provisória (cumprimento provisório), procurou o legislador dispensar a caução nas hipóteses deste artigo, contudo, poderá a situação gerar séria e profunda injustiça, tendo em vista que o executado irá trocar o certo (bem que era de sua propriedade e que foi penhorado para garantir o cumprimento provisório) pelo duvidoso (futuro cumprimento de sentença invertido visando o ressarcimento dos danos provenientes da execução considerada injusta), ficando, inclusive, sujeito a toda sorte do sistema de cumprimento (como a localização de bens, nova penhora, nova execução até o efetivo reembolso - se houver - do valor correspondente ao bem expropriado judicialmente).

Este é um risco que o procedimento voltado para a maior celeridade executiva poderá gerar, baseado na pouca probabilidade de sucesso da tese jurídica discutida no recurso pendente de julgamento sem efeito suspensivo ${ }^{19}$.

Nestas situações, portanto, ocorre a formação de título executivo em favor do demandado originário que, na fase de cumprimento de sentença (com prévia liquidação para apurar o quantum debeatur), será tratado como exequente.

Deve-se, com isso, ter bastante cautela na utilização das tutelas provisórias ou mesmo no cumprimento provisório da sentença, tendo em vista a possibilidade natural de inversão dos polos e constituição de título executivo em favor do demandado originário.

As posições processuais dos demandantes originários, e de eventuais terceiros na fase de conhecimento, podem se alterar a depender da circunstância ocorrida durante o andamento do processo. Por tais razões, ratifica-se o entendimento de que o processo (como um todo) deve ser observado como módulos processuais, em que as posições, os sujeitos e os intervenientes podem alterar.

\footnotetext{
${ }^{19}$ Sobre o assunto, observou Zavascki, comentando a antiga redação do art. 588 do CPC/1973 (e que tem aplicação às situações previstas no art. 521, do CPC/2015) que: "as providências para o retorno dos fatos ao estado anterior desenvolvem-se nos mesmos autos, independentemente de nova ação. Pode ocorrer que seja impossível a reposição in natura (por exemplo, se houver perecimento do objeto penhorado, ou se já foi transferido a terceiro, que o tenha arrematado), hipótese em que não se terá outra alternativa que não a de converter o dever de restituir em obrigação de pagar danos. Nesse caso, o quantum a ser indenizado será apurado em liquidação e cobrado, se for o caso, pelo procedimento da execução por quantia certa. Esse mesmo modo de proceder é o cabível quando, desfeita a execução provisória e repostos os fatos ao estado anterior, ainda restarem danos indenizáveis: a ação liquidatória e a subseqüente execução dar-se-ão nos mesmos autos. É o que estabelece, de modo expresso, o inciso IV". Comentários ao código de processo civil. 2. ed. São Paulo: Revista dos Tribunais, 2003. v. 8. p. 240.
} 
Em última análise, a posição processual (eventual certificação de direito ou dever) do réu pode alterar durante o andamento da litispendência, o que gera a necessidade de análise com parcimônia, visando concluir se houve ou não a constituição de algum direito a seu favor, nos termos do previsto no art. 515, I, do CPC.

Existem inúmeras situações em que as posições processuais originárias podem inverter, o que deve ser objeto de análise e reflexão acerca das estratégias processuais de cada caso concreto. A fase de cumprimento da decisão judicial não trará, necessariamente, a estabilização dos polos processuais que estavam presentes na fase de conhecimento: tudo dependerá das múltiplas situações de cada caso concreto, como tratado neste texto.

\section{Conclusões}

A reconvenção é ação do réu em face do autor no mesmo processo, gerando uma cumulação ulterior de pedidos que devem, em regra, ser julgados na mesma sentença.

Se o réu tem pretensão em desfavor do autor sem qualquer aderência (conexão) em relação à causa originária, não deve apresentar reconvenção, e sim demanda própria, sem que ocorra a preclusão. Da mesma forma, mesmo em caso de conexão, o réu pode preferir demandar de forma autônoma, sem prejuízo da distribuição por dependência (arts. 55, $\S 1^{\circ} \mathrm{e}$ $3^{\circ}$, do CPC).

Não é obrigatória a propositura de reconvenção, mesmo estando presentes seus requisitos, tratando-se de mera oportunidade processual assegurada ao réu.

O sistema processual labora com o binômio risco $x$ responsabilidade, pelo que o réu tem o ônus de contestar e reconvir na mesma peça processual.

Apesar da indicação contida no caput do art. 343, do CPC, não há óbice à apresentação tão-somente da reconvenção, sofrendo o réu as consequências de sua conduta omissiva em relação aos fatos alegados pelo autor em sua inicial. Será, portanto, revel na ação, e reconvinte, sendo o seu contra-ataque suficiente para afastar os efeitos da revelia em relação aos fatos comuns (arts. 341 e 344, do CPC).

Não pode o autor, sabedor do risco e responsabilidade de demandar em juízo, se beneficiar pela sua própria atuação açodada em caso de apresentação de reconvenção. 
A resolução parcial deve ser admitida nos casos em que a cumulação de pedidos advém de conduta do réu, com o procedimento previsto no art. 356, do CPC, o que também será objeto de enfrentamento em capítulos seguintes deste curso.

Outras diversas situações jurídicas permitem a constituição de título executivo em favor do réu originário, gerando, inclusive, liquidação e cumprimento de sentença invertidos.

Nos casos em que se admite pedido contraposto, a preocupação do legislador é com a simplificação procedimental.

A possibilidade de variação das posições processuais também ocorre nos casos de ações dúplices, em que, pela própria natureza do direito material, a simples improcedência do pleito do autor já certifica direito em favor do réu.

Outrossim, caso o autor obtenha a seu favor uma tutela provisória, há, em verdade, uma antecipação provisória de uma situação ligada ao futuro bem jurídico, que poderá ou não ser confirmado. Nesta hipótese, é possível a formação de título executivo invertido quando a confirmação não ocorrer, com possibilidade de liquidação e indenização dos danos causados ao réu no mesmo processo.

A posição processual (eventual certificação de direito ou dever) do réu pode alterar durante o andamento da litispendência, o que gera a necessidade de análise com parcimônia, visando concluir se houve ou não a constituição de algum direito a seu favor, nos termos do previsto no art. 515, I, do CPC.

\section{REFERÊNCIAS}

ARAÚJO, José Henrique Mouta. Objeto litigioso do processo: reflexões sobre o tema. In Teoria do Processo - panorama doutrinário mundial, vol 2. Fredie Didier Jr (organizador). Salvador: Juspodivm, 2010.

Anotações sobre a nova disciplina da execução provisória e seus aspectos controvertidos. Revista Dialética de Direito Processual n. 14. maio. São Paulo: Dialética, 2004.

ASSIS, Araken de. Processo civil brasileiro. Vol III, parte especial: procedimento comum. São Paulo: Revista dos Tribunais, 2015. 
BONDIOLI, Luis Guilherme Aidar. Reconvenção no processo civil. São Paulo: Saraiva, 2009.

DIDIER JR, Fredie. Contradireitos, objeto litigioso do processo e improcedência no CPC2015. In Improcedência. MOUZALAS, Rinaldo; SILVA, Beclaute Oliveira e MARINHO, Rodrigo Saraiva. Salvador: Juspodivm, 2015.

. Curso de Direito Processual Civil vol 1. 17ª edição. Salvador: Juspodivm, 2015.

FIGUEIRA JÚNIOR, Joel Dias e LOPES, Maurício Antônio Ribeiro. Comentários à lei dos juizados especiais cíveis e criminais. 3. ed. São Paulo: RT, 2000.

LUCON, Paulo Henrique dos Santos. Relação entre demandas. $2^{\mathrm{a}}$ edição. Brasília: Gazeta Jurídica, 2018.

MALAFAIA, Evie Nogueira e. Comentário ao art. 343. Novo código de processo civil comentado - Tomo II (art. 318 ao art. 770). RIBEIRO, Sergio Luiz Almeida; GOUVEIA FILHO, Roberto Pinheiro Campos; PANTALEÃO, Izabel Cristina; GOUVEIA, Lucio Grassi de (coords). São Paulo: Lualri, 2017.

NEVES, Daniel Amorim Assumpção. Novo Código de Processo Civil comentado artigo por artigo. $2^{\text {a }}$ edição. Salvador: Juspodivm, 2017, pp. 623-624.

WATANABE, Kazuo. Ação dúplice. Revista de Processo. n. 31. São Paulo: Revista dos Tribunais, 1983.

WAMBIER, Luiz Rodrigues e TALAMINI, Eduardo. Curso avançado de processo civil. Vol 2, 18ª edição. São Paulo: Revista dos Tribunais, 2019.

ZAVASCKI, Teori Albino. Comentários ao código de processo civil. 2. ed. São Paulo: Revista dos Tribunais, 2003. v. 8. 